\title{
Empowering Makers - A Design Science Approach
}

\author{
Claudia Kaar \\ Institute of Business Informatics - Communications \\ Engineering, Johannes Kepler University, Linz, Austria \\ Claudia.Kaar@jku.at
}

\begin{abstract}
The advent of makerspaces has increased access and utilization of facilities for digital production. They can be of benefit for timely education, not only for qualifying existing workforce in production industries, but also for attracting students in production-related domains. We discuss the case of a regional makerspace and its first evaluation study to propagate additive manufacturing through a structured while individualized education scheme. Thereby, additive manufacturing capacity building starts with individual goal setting and structuring requirements for an envisioned solution which becomes part of a learning contract of a specific project. Learning steps are framed by design science stages and cycles, since artefacts in making can be of various kinds, stemming either from construction, modeling, material, or manufacturing exploration. The evaluation study revealed essential benefits in terms structured planning and individualization of capacity building processes.
\end{abstract}

\section{CCS CONCEPTS}

- Human-Centered Computing; • Collaborative and Social Computing; • Applied Computing; • Education; • Information Systems; • Information Systems Applications;

\section{KEYWORDS}

Makerspace, Project-based Learning, Capacity Building, Additive Manufacturing, Design Science

\section{ACM Reference Format:}

Claudia Kaar and Christian Stary. 2020. Empowering Makers - A Design Science Approach. In 2020 3rd International Conference on Education Technology Management (ICETM 2020), December 17-19, 2020, London, United Kingdom. ACM, New York, NY, USA, 6 pages. https://doi.org/10.1145/3446590.3446606

\section{INTRODUCTION}

'Making' aims for learning new skills [1] and to "engage in the creative production of artifacts" [2] utilizing novel material or/and new technologies. In makerspaces, interested people engage in conversation with peers. They share their ideas, construct, and finally build their individual products in such collaborative settings [1]. By blending "digital and physical technologies to explore ideas, learn technical skills, and create new products" [3], engagement and knowledge sharing are promoted in socio-technical settings and system designs [4], [5]. The latter is crucial for an organizational

This work is licensed under a Creative Commons Attribution-NonCommercialNoDerivs International 4.0 License.

ICETM 2020, December 17-19, 2020, London, United Kingdom

(C) 2020 Copyright held by the owner/author(s).

ACM ISBN 978-1-4503-8875-7/20/12.

https://doi.org/10.1145/3446590.3446606

\author{
Christian Stary \\ Institute of Business Informatics - Communications \\ Engineering, Johannes Kepler University, Linz, Austria \\ Christian.Stary@jku.at
}

context when workers explore and learn about new technologies (cf. [6], [7]).

Engaging people to produce artefacts, e.g., through project-based learning [8] and problem-based learning [9], could empower them to become entrepreneurs and promote such processes [10] - a conditio-sine-qua-non in education and organizational development in the upcoming economic era (cf. [11]). Empowerment provides a learner with the authorized capability to perform and share certain activities while enabling individual self-realization [12]. It requires learner-centered support beyond technology skill training which has not been at the center of research so far (cf. [13]).

In this paper, we investigate education in makerspaces introducing a design science perspective on project-based learning. In Section 2, we provide some background on facilitating Additive Manufacturing (AM) capacity building before framing additivemanufacturing learning processes by design science research cycles in Section 3. Exploration and critical reflection are promoted based on learning contracts and self-managed artefact design-evaluation roundtrips. In Section 4, we report on a field study evaluating project-based Business Informatics student experiences on AM. Section 5 reflects on the results which are discussed in Section 6. We conclude with topics for further research in Section 7.

\section{MAKER CAPACITY BUILDING IN ADDITIVE MANUFACTURING}

In this section, we review constructionist learning (support) informing our approach and the contextual stages for individual capacity building in Additive Manufacturing (AM) from an empowering maker perspective. According to Kurti et al. [14], hands-on construction is grounded in the self-organization of learning while leading to sustainable and appealing creation of knowledge [15] based on individual experiences and interactions [16]. However, such learning processes cannot easily be standardized, they are rather non-linear due to their cognitive and social nature [17]. Accepting or provoking temporary disturbances can be resolved through providing resources which support reflective thinking, thus meta-cognitive processes [18].

Taking into account social and cognitive factors in learning, the situated cognition theory (cf. [19]) has been proposed framing self-regulated capacity building processes with social, cultural, and physical contexts. Schuitema et al. [20] report on a positive relationship between autonomy support and relevance and self-regulated capacity building. Recently, the process nature of self-regulated learning has been underlined by stating that most of the respective model "[...] include the basic assumption that learning is primarily a process (and not merely a result) composed of varying combinations of static individual characteristics and skills that contribute to performance" [21]. Various models on self-regulated learning have 


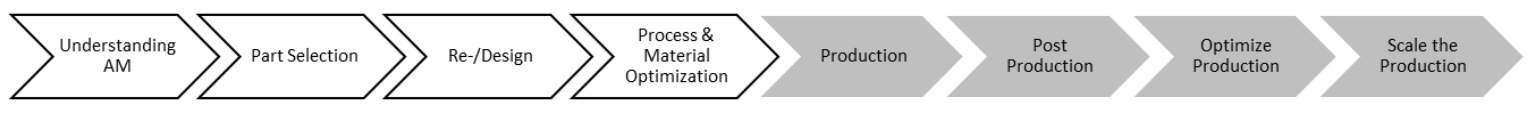

Figure 1: Stages in Additive Manufacturing capacity building

been proposed since then, mainly conceptualizing it as recurring cycle of three to four stages, including self-evaluation and monitoring, goal setting and strategic planning, strategic implementation and monitoring, as well as strategic outcome monitoring [22-24]. For instance, Winne and Hadwin [25] have proposed a four-stage model distinguishing between task definition, goal setting and planning, enacting study tactics and strategies, and meta-cognitive adaption for future learnings. In the first stage, information on conditions related to the task is processed by the learner. In this regard, not only task-specific conditions (e.g., time constraints) but also cognitive as well as motivational conditions are of relevance.

Considering the process of self-regulated capacity building, a general pattern reveals three main phases [24]. All models require some kind of preparation phase at the beginning, which is then followed by the performance or execution phase. Finally, an appraisal phase allows for adaptations with respect to applied learning strategies and plans for the purpose of increasing one's effectiveness. For instance, the model proposed by Winne and Hadwin [25] first requires the processing of conditions related to a specific task, followed by some kind of goal setting and planning procedure (cf. [25], [26]). These stages are subject to the preparatory phase as they are essential to the actual execution of learning strategies and plans.

Even though technology skill training dominates education in makerspace (https://project-manus.mit.edu/wp-content/uploads/ 2017/09/MIT-Project-Manus-Annual-Report-fin.pdf), they aim for learner inspiration and immersion [6]. Following these objectives, our approach should trigger playful engagement of learners when they explore their unique interests and pursuits, including the possibility to fail in implementing particular ideas. Although it is out of question that training is important for expensive production machinery, and an issue well addressed by providers of AM equipment, empowering people to solve a problem in its original context should be part of education [14]. Recent studies refine makerspaces to knowledge spaces [12], pre-structure learning processes [27], in particular for exploring material, designs, and revisiting production planning [28]. Taking these inputs into account the capacity building process of makers has several phases (see Figure 1) referring to preparation (white process steps) and (post-)production (grey process steps) [29].

Phase 1: Understanding Additive Manufacturing. Before going into production, makers need to understand the basic principles of AM. The basic concepts include printing technologies, different materials, and a dimensional perspective. Whereas the printing technology decides which materials are suitable, the dimensional perspective stays the same. The technology varies from fused deposition modeling, stereolithography, to selective laser sintering. Depending on the desired object, each technology offers unique specifications to consider. Moreover, the material choice differs depending on the technology. Essential for every 3D print and model is the awareness of the three dimensions, i.e., width, height, and depth.

Phase 2: Part Selection. In addition to understanding the basic concepts of AM the desired object needs to be broken down to individual printable parts. Apart from the high variety of functionalities of 3D printers, not every object is feasible to be printed.

Phase 3: Re-/Design. The design and/or redesign phase is necessary to build a 3D model convert it to a printable file. There are several methods available to generate a 3D model, e.g., modeling with a 3D software, or 3D scanning of an object. Different printing parameters and sometimes scaffolds, to steady the objects, need to be considered. Furthermore, this phase can be revisited to optimize one's object.

Phase 4: Process \& Material Optimization. The preceding phases allow to understand and design the desired object. By enabling the maker to have a clearer idea of an object, this phase decides on what technology and materials to use. The context and usage of the objects determine the appropriate printer and material, which can vary, e.g., to make it more robust, water-resistant or even flexible.

Phase 5: Production. In the actual printing process the 3D printer will be set up with the chosen material, and the model is transferred to it, ensuring the required amount of material.

Phase 6: Post Production. The post production phase triggers the remaining finishing touches of the objects. Some technologies require to cure and therefore harden the object or remove scaffolds. Moreover, objects can be sealed with specific paint or powder to make it more resistant to environmental influences.

Phase 7: Optimize Production. For an individual maker, the process ends with performing post production activities. However, makerspaces are often used as testbeds for organizations to gain insights about new technologies. Organizations can optimize their production by re-designing their object, rethinking certain parameters or refining post production phases.

Phase 8: Scale the Production. The last phase shifts the focus to future development. Since the production industry currently explores Industry 4.0 settings, companies need to design their products according to new technological capabilities. This stage offers the space to explore networked and self-adaptive production.

\section{FRAMING MAKER AM-CAPACITY BUILDING BY DESIGN SCIENCE}

Design Science has attracted intense attention for the last decade (cf. [30], [31]). Its dual while iterative nature with respect to design artifacts and design theory equally supports practical development and conceptual advancement. The Relevance Cycle (Figure 2) connects the environment of the maker (project) with the core development activities. The Rigor Cycle relates these activities to a knowledge base informing the project. The Design Cycle iterates between the core development activities (building and evaluating artifacts). 


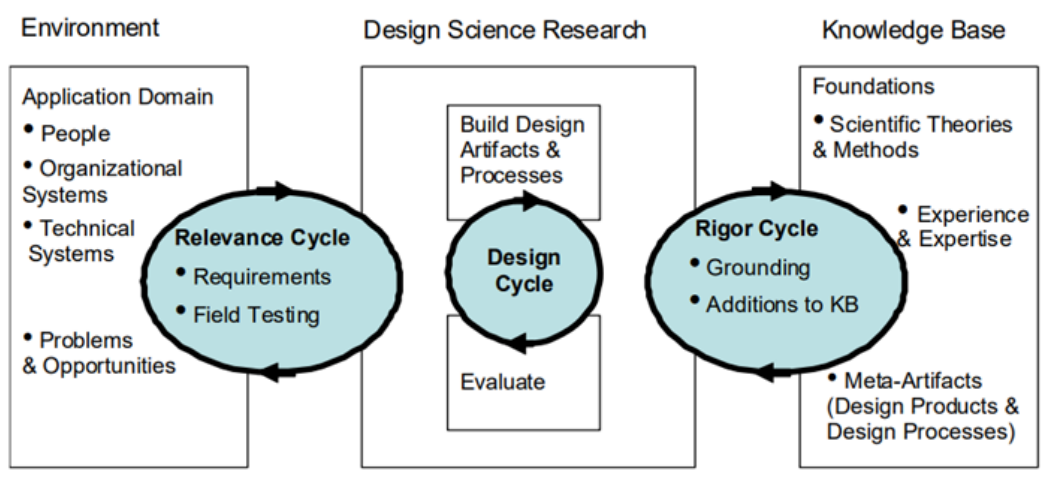

Figure 2: Design cycles embodied in pragmatic and methodological context (from [31])

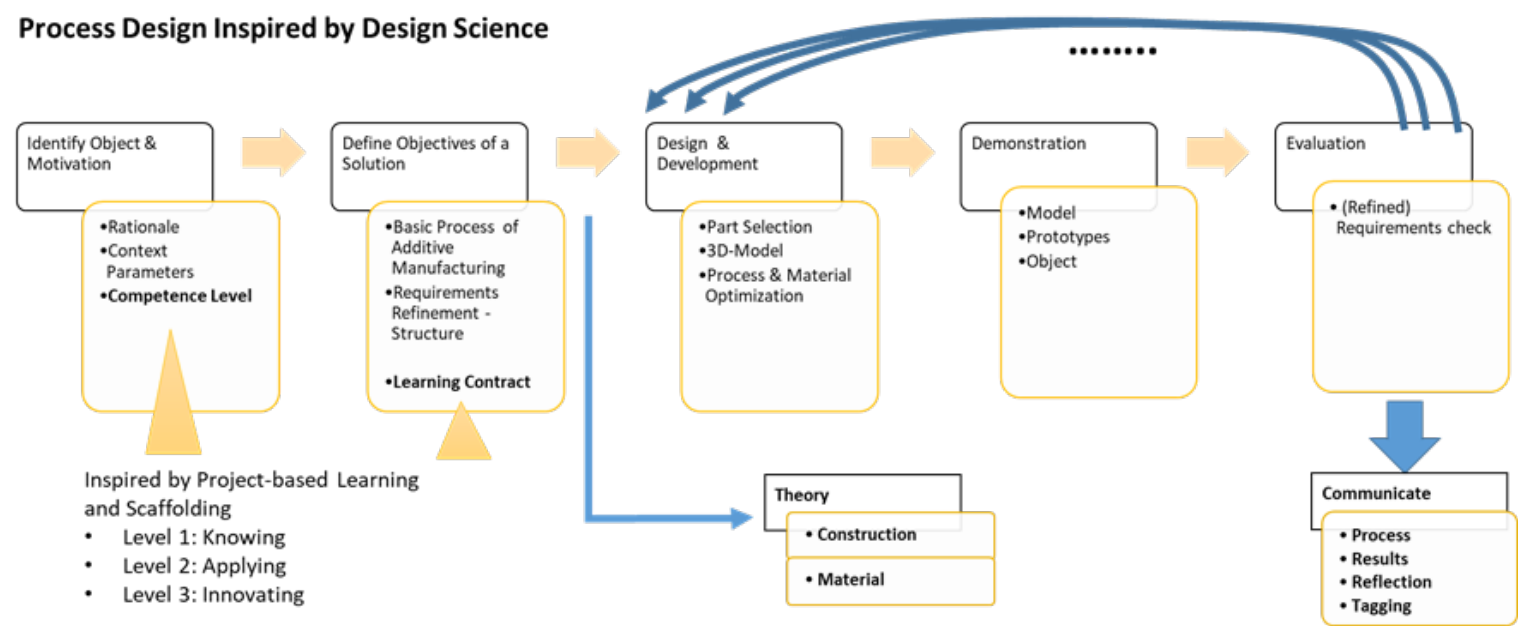

Figure 3: Process design inspired by Design Science

The original framework has been operationalized by Peffers et al. [32] allowing us to frame the AM learning stages as shown in Figure 3. As contracted, learners organize the capacity building process facilitated by a mentor. Learning is triggered by a maker's interests in AM. Each project starts with systematically developing a specific goal, defining learning milestones and interventions for reflecting on achievements and clarification. In this stage also competencies are addressed: Knowing refers to having knowledge and fundamental understanding. Applying empowers a maker planning and producing an artefact by utilizing AM in an informed way. Innovating features novel developments by means of AM technologies. In order to structure the activities in the project and convey the capabilities of AM, a learning contract is negotiated between all project members and the persons responsible for each project. It is documented and signed by all parties. The documented learning outcomes also provide the basis for evaluating the project results.

A learning contract is composed of:

1. Project organization: Name of project, duration, f2frequirements, credits, contact, role(s) in the project, relation to other project groups or projects.
2. Current level of competence: 1 - Knowing, 2 - Applying, 3 Innovating.

3. Project objectives including justification and desired competence level.

4. Content-related activities referring to technical work (construction, material, production) and (re)search.

The design cycle activities within the project work can be of various type:

1. Working with provided content: Elaborating the content that belongs to the project. This content is available to makers at any time in the course of their project, and thereafter for self-studies in the form of videos, multimedia documents, additional resources, and examples. Usually, content is studied in individual learning phases prior to interaction or attendance phases. It is prepared according to project-specific questions (to facilitators or peers) for effective knowledge creation.

2. Project Management: In the course of their project work, all makers acquire competences in planning, calculation, execution, evaluation, and evaluation of projects. 
3. Applying acquired content in the context of project work. In case support is needed the facilitator or mentor and, where required, experts can be contacted in addition to peers. The learning contract provides a structure for evaluation and reflection, including the learning process, and thus, metacognitive aspects.

The project work can be accomplished in various forms:

1. Self-study: Each learner acquaints him/herself with the relevant knowledge content for his or her concern. Content is prepared for capacity building as well as created by learners in the course of their project work. Due to the direct relation to the practical questions and the respective concrete research process, content is mainly recognized in its respective project context and can therefore be perceived sustainably.

2. Peer-to-peer setting: The learners are part of communities they may organize themselves in order to collaboratively plan and design the implementation of the projects. The group affiliation, the bottom-up sense of community, and the responsibility of each individual for the success of the project work of the group is intended to increase the intrinsic motivation of individual learners and thus the efficiency and self-efficacy the capacity building process.

3. Face-to-face meeting: Personal meetings of learners with mentors or facilitators are part of the capacity building process. In particular, workshops help to digest self-paced content that is linked to practical project tasks.

4. Knowledge transfer phases: Each project is documented in a shared memory, both from a process and results' perspective. Both can contribute to future designs.

\section{FIELD STUDY}

In this section, we describe our first field study with the presented approach. It has been run under the supervision of a Business Informatics lecturer as part of a class in practicing distributed system engineering. We detail the setting and stages, and report on the design cycles as experienced by the learners.

\subsection{Setting}

The study was conducted in a semester-long class for Business Informatics students in their third year. Six groups with two or three students were asked to extend their competences in AM and sensor technologies by visiting a regional makerspace. The objectives of this class were to design and build a distributed system to apply previously learned knowledge and get a first hands-on experience. The students were asked to complete a learning diary realized by the open ePortfolio system Mahara (mahara.org), to document their learning process. The teams were able to create their own portfolio and journals throughout the semester to report on the progression of their competence development. Guiding questions were provided to help students complete their learning diaries. The items were specifically designed for a project to be implemented in a makerspace. They contain general questions about the specific work process and milestones, and specific items concerning the maker competence and the utilization of the makerspace facility.

\subsection{Study Design}

Stage 1: Identify Object \& Motivation: Students were first introduced to the class objective to design and build a distributed system, by combining AM and sensor technologies. The students were invited to join the regional makerspace to explore their options and identify their project ideas. The makerspace hosts gave a first overview of possible projects and introduced the available technologies and the respective parameters. The teams could explore the makerspace and discuss desired learning goals and competencies they wanted to achieve. The project ideas had to contain a rationale, to further describe the need and goal of the project. Furthermore, context parameters to successfully design and build the object were discussed with the hosts and teacher. In this stage, the students gained deeper knowledge about their competence level and developed first ideas about their project design.

Stage 2: Define Objectives of a Solution: After visiting the makerspace, students were asked to complete their learning contracts. It includes questions about the project idea, competence level and desired goal, resources, milestones, and documentation. The teacher reviewed the contracts and improved them in case inconsistencies were found. A crucial part of the learning contracts are the milestones. The first milestone required the students to obtain an understanding of used technologies, materials, and overall resources for AM. The second and third milestones determined the progress developing the desired objects and served as basis for assessment. When achieving a milestone, the teacher invited the students for a feedback discussion to review their work. Furthermore, the outcome of this stage were a first concept and construction ideas for the projects. After the learning contracts were signed, the students were asked to work on their projects in a self-regulated way.

\section{Cycle 1: Achieving Milestone 1}

Stage 3: Design \& Development: As mentioned before, the objective of this class was to design and build an object using AM and sensor technologies. Before modeling and printing, the teams had to familiarize themselves with the available technologies. The objective of milestone 1 was to acquire the required knowledge to successfully manufacture their envisioned object in the project. Therefore, students started to gain knowledge by using online sources, such as videos, tutorials and other various information. Furthermore, students visited the makerspace and talked to the hosts about their design ideas. The outcome of this phase were the results of their search and various design choices and technology decisions.

Stage 4: Demonstration: Throughout the collection of information, some student groups decided to print some kind of object, which they found online. They wanted to see the printing process and feel the material, to decide whether the proposed AM approach is feasible for their ideas. Furthermore, the students assembled their portfolio with their learnings and acquired knowledge.

Stage 5: Evaluation: As mentioned before, the students discussed their conceptual part of the milestone and their technology decisions in the feedback discussion with the teacher. The teacher, acting as a mentor in this stage, provided deeper insight into the subject, additional inputs and feedback to their project ideas, when guidance was demanded. Afterwards, students were asked to design 
and print their first prototypes entering the second cycle of the Design Science process.

\section{Cycle 2: Achieving Milestone 2}

Stage 3: Design \& Development: In the next cycle of their project, the students designed their first prototypes using a 3D modeling software. Few students acquired knowledge about the used program via Internet sources. Some students decided to visit a workshop which was hosted by the regional makerspace. The workshop provided first modeling guidelines and helped students to design their objects according to the intended use. The makerspace also provides a room with computers and useful gadgets to facilitate modeling objects. Some groups used this facility and asked for help with their designs from the makerspace hosts.

Stage 4: Demonstration: After completing their first designs, students started to print their models. One group decided to print a miniature version to find out whether the applied parameters fulfill the required structure and robustness criteria. The makerspace hosts helped the teams to prepare and correctly start the 3D printer. Here the hosts gave insights into the printing process and explained the various parameters for a successful print job. Moreover, some students completed a post-production process by clearing the objects of scaffolds and other residues.

Stage 5: Evaluation: After the teams concluded their first print process, the objects were evaluated for their viability. It appeared that some groups designed the holes for the sensors too small, or the printed box did not close at all. Another team decided to redesign their ideas in way the object could withstand different weather conditions. Consequently, all groups decided to redesign and -print their objects according to their newly gained insights. The first prototypes were discussed in the feedback session with the teacher. Failures and success stories from the first trial were shared for redesigning. Teacher inputs helped the learners to proceed.

\section{Cycle 3: Achieving Milestone 3}

Stage 3: Design \& Development: In the preceding step, the students had found out that a redesign of their object is necessary. The gained knowledge was used to identify the flawed design parameters. The aforementioned holes for the sensors were enlarged, others completely redesigned their box to close correctly. Some groups changed the infill of the objects to develop a more robust product. Furthermore, the students invested more time to think about the post-production process. One group rethought their material choice, to withstand environmental influences. Other groups placed the object in the printer differently, to minimize the use of scaffolds and printing time.

Stage 4: Demonstration: After completing their redesigns, the students printed another prototype. Most of the students consulted the hosts again, to confirm the validity of their selected parameters The printed objects were cleared again of residues and scaffolds.

Stage 5: Evaluation: After completing their latest print job, the students evaluated their prototypes with respect to the documented statements in the learning contracts. Some groups had changed their plan when completing the project. In this case, the groups had to write down their learning path and the parameters they needed to change. In the feedback discussion, the students explained their modified processes and had to argue for their design decisions. It seems to be an effective way to handle unpredicted scenarios, as the students learn to explain and communicate development processes that deviate from contracted plans.

\section{RESULTS}

The findings showed that all students regardless of the kind of project they were working on, completed at least three cycles of the Design Science process. The cycles were derived from the milestones the students had to achieve. The initial two phases were preparation stages, whereas the other phases were part of completed design cycles. In reference to the AM stages as shown in Figure 1 students only went as far as the post-production phase. It was not intended to implement an optimized and scaled production, as these refer to industry projects.

It turned out, even though students had gained knowledge before starting to work on their projects, that they needed help, either by a host, through Internet source, or their mentor. The most common way to find information was searching the web and selecting videos or tutorials, whereas personal assistance was mostly provided by the makerspace hosts. They ensured proper print preparation and production for each team.

Reflecting on the gained knowledge and the competence levels, students confirmed that their level of competence in the field of AM has increased significantly. Some of the students decided to buy a 3D printer for personal use.

The Design-Science approach seems to help students efficiently structure their AM tasks. The cycles helped the students to understand the different milestones and the required sub goals before actually $3 \mathrm{D}$ printing objects. The approach to complete three cycles seems to be efficient with respect to the capacity building process in the AM domain. The first cycle improves conceptual understanding and provides fundamental experience. The subsequent cycles focus on the prototype itself. Hereby, the second cycle serves the purpose of a first trial producing the object, and the third one for a refined version of the object based on previous experiences.

\section{DISCUSSION}

The study shows an increase of learner knowledge in Additive Manufacturing and a successful demonstration of the different DesignScience cycles in terms of structuring a project of their own and planning its development according to digital production needs and capabilities. Overall, the cooperation with the regional makerspace was sufficient for the student groups to complete their projects. With respect to the curriculum, students reported they had never experienced a class like this before. Moreover, the open concept was appreciated. The students were able to overcome difficulties which came up when working on the project in a self-organized way. The approach also showed that students had fun and liked working on projects they had proposed individually. The groups were reflective about their competences, failures, and successes, and were able to transform experienced failures to knowledge gains in a self-regulated way.

The students were asked to hand-in a learning diary about their work at the makerspace. None of the students had been familiar with the concept of learning diaries when starting to work on the project. Therefore, input and work instructions had to be given. It helped them answering the provided questions. Moreover, students 
had to get acquainted with the software solution, which was not considered at first by the lecturer. Overall, the learning diaries were completed successfully. For future learning experiences, the goals of portfolio work and learning diary entries need to be revisited to better communicate the intention of the respective tasks.

Although in coordination with the makerspace team, details about the class setting and the requirements for learners had been laid out, discussed, and agreed upon, some makerspace hosts and employees were not sufficiently briefed. Consequently, some student groups experienced organizational difficulties when starting to work at the makerspace location. However, the hosts from the respective stations were helpful to the students and facilitated learning how to work with certain materials and how to handle 3D printing.

Overall, all objects could be printed and presented successfully. The feedback discussions with the lecturer seem to be necessary to be well informed of each project and guide the students for further work, although the design cycles supported the planning and organization of the AM project work quite well.

\section{CONCLUSION}

Capacity building settings for empowering makers require contextsensitive structuring. Based on a constructionist learning concept we have framed project-based making by Design-Science cycles. It considers capacity building as bootstrapping process for economically viable production in a self-organized and meta-cognitively reflected way. The reported field study confirmed the feasibility and effectiveness of Design-Science-based learning cycles, since learners could experience accurate feedback along their path to successfully finishing their individual projects. However, further empirical studies need to be set up and designed to identify individual learning support needs and evaluate corresponding adaptation features.

\section{REFERENCES}

[1] D. Dougherty, "The Maker Movement," Innov. Technol. Gov. Glob., vol. 7, no. 3, pp. 11-14, Jul. 2012, doi: 10.1162/INOV_a_00135.

[2] E. R. Halverson and K. Sheridan, "The Maker Movement in Education," Harv. Educ. Rev., vol. 84, no. 4, pp. 495-504, Dec. 2014, doi: 10.17763/haer.84.4.34j1g68140382063.

[3] K. Sheridan, E. R. Halverson, B. Litts, L. Brahms, L. Jacobs-Priebe, and T. Owens, "Learning in the Making: A Comparative Case Study of Three Makerspaces," Harv. Educ. Rev., vol. 84, no. 4, pp. 505-531, Dec. 2014, doi 10.17763/haer.84.4.brr34733723j648u.

[4] U. Cress, J. Moskaliuk, and H. Jeong, Eds., Mass Collaboration and Education. Cham: Springer International Publishing, 2016.

[5] K. A. Peppler, E. Halverson, and Y. B. Kafai, Eds., Makeology: Makerspaces as learning environments. New York: Routledge, 2016.

[6] M. Kayler, T. Owens, and G. Meadows, "Inspiring Maker Culture through Collaboration, Persistence, and Failure," in Proceedings of Society for Information Technology \& Teacher Education International Conference 2013, New Orleans, Louisiana, United States, Mar. 2013, pp. 1179-1184, [Online]. Available: https://www.learntechlib.org/p/48281.

[7] C. Pacchi, "Sharing economy: Makerspaces, co-working spaces, hybrid workplaces, and new social practices," in Milan: Productions, Spatial Patterns and Urban Change, S. Armondi and S. Di Vita, Eds. London: Routledge, 2017, pp. 73-78.

[8] J. S. Krajcik and P. C. Blumenfeld, "Project-Based Learning," in The Cambridge Handbook of the Learning Sciences, R. K. Sawyer, Ed. Cambridge: Cambridge University Press, 2005, pp. 317-334.

[9] H. S. Barrows and R. M. Tamblyn, Problem-Based Learning: An Approach to Medical Education. Springer Publishing Company, 1980.
[10] J. S. Hui and E. M. Gerber, "Developing Makerspaces as Sites of Entrepreneurship," in Proceedings of the 2017 ACM Conference on Computer Supported Cooperative Work and Social Computing - CSCW'17, Portland, Oregon, USA, 2017, pp. 20232038, doi: 10.1145/2998181.2998264.

[11] R. M. Lee and Y. Yuan, "Innovation Education in China: Preparing Attitudes, Approaches, and Intellectual Environments for Life in the Automation Economy," in Higher Education in the Era of the Fourth Industrial Revolution, N. W. Gleason, Ed. Singapore: Springer Singapore, 2018, pp. 93-119.

[12] I. Fourie and A. Meyer, "What to make of makerspaces: Tools and DIY only or is there an interconnected information resources space?" Libr. Hi Tech, vol. 33, no. 4, pp. 519-525, Nov. 2015, doi: 10.1108/LHT-09-2015-0092.

[13] O. Stickel, M. Stilz, and V. Pipek, "MuC-Makerspace: Academic practices in Community Innovation and (Digital) Fabrication," 2017, doi: 10.18420/muc2017ws16-0429.

[14] R. S. Kurti, D. L. Kurti, and L. Fleming, "The Philosophy of Educational Makerspaces: Part 1 of Making an Educational Makerspace," Teach. Libr., vol. 41, no. 5, pp. 8-11, 2014.

[15] M. Boekaerts, "Emotions, Emotion Regulation, and Self-Regulation of Learning," in Handbook of Self-Regulation of Learning and Performance, B. J. Zimmermann and D. H. Schunk, Eds. New York, NY: Routledge, 2011, pp. 408-425.

[16] P. A. Ertmer and T. J. Newby, "Behaviorism, Cognitivism, Constructivism: Comparing Critical Features From an Instructional Design Perspective," Perform. Improv. Q., vol. 26, no. 2, pp. 43-71, 2013, doi: 10.1002/piq.21143.

[17] M. Schcolnik, S. Kol, and J. Abarbanel, "Constructivism in Theory and in Practice," Engl. Teach. Forum, vol. 44, no. 4, pp. 12-20, 2006.

[18] M. Laanpere, H. Põldoja, and P. Normak, "Designing Dippler - A NextGeneration ${ }^{\mathrm{TEL}}$ System," in Open and Social Technologies for Networked Learning, Berlin, Heidelberg, 2013, pp. 91-100.

[19] J. S. Brown, A. Collins, and P. Duguid, "Situated Cognition and the Culture of Learning," Educ. Res., vol. 18, no. 1, pp. 32-42, Jan. 1989, doi: 10.3102/0013189X018001032.

[20] J. Schuitema, T. Peetsma, and I. van der Veen, "Self-regulated learning and students' perceptions of innovative and traditional learning environments: a longitudinal study in secondary education," Educ. Stud., vol. 38, no. 4, pp. 397-413, Oct. 2012, doi: 10.1080/03055698.2011.643105.

[21] H. Järvenoja, S. Järvelä, and J. Malmberg, "Understanding Regulated Learning in Situative and Contextual Frameworks," Educ. Psychol., vol. 50, no. 3, pp. 204-219, Jul. 2015, doi: 10.1080/00461520.2015.1075400.

[22] R. Azevedo, R. F. Behnagh, M. Duffy, J. M. Harley, and G. Trevors, "Metacognition and Self-Regulated Learning in Student-Centered Learning Environments," in Theoretical Foundations of Learning Environments, 2nd ed., D. Jonassen and S. Land, Eds. New York, NY: Routledge, 2012, pp. 171-197.

[23] J. Beishuizen and K. Steffens, "A Conceptual Framework for Research on SelfRegulated Learning," in Self-Regulated Learning in Technology Enhanced Learning Environments: A European Perspective, R. Carneiro, P. Lefrere, K. Steffens, and J. Underwood, Eds. Rotterdam: SensePublishers, 2011, pp. 3-19.

[24] M. Puustinen and L. Pulkkinen, "Models of Self-regulated Learning: A review," Scand. F. Educ. Res., vol. 45, no. 3, pp. 269-286, Sep. 2001, doi: 10.1080/00313830120074206.

[25] P. H. Winne and A. F. Hadwin, "Studying as Self-Regulated Learning," in Metacognition in Educational Theory and Practice, D. J. Hacker, J. Dunlosky, and A. C. Graesser, Eds. Mahwah, N.J: Lawrence Erlbaum Associates Publishers, 1998, pp. 27-30.

[26] P. H. Winne and N. E. Perry, "Measuring Self-Regulated Learning," in Handbook of Self-Regulation, Elsevier, 2000, pp. 531-566.

[27] D. Smay and C. Walker, "Makerspaces: A creative approach to education," Teach. Libr., vol. 42, no. 4, pp. 39-43, Apr. 2015.

[28] M. Carulli, M. Bordegoni, M. Bianchini, P. Bolzan, and S. Maffei, "A novel educational model based on 'knowing how to do' paradigm implemented in an academic makerspace," vol. 34, pp. 7-29, 2017.

[29] C. Stary, G. Weichhart, and C. Kaar, "Design Science as Methodological Approach to Interoperability Engineering in Digital Production," in On the Move to Meaningful Internet Systems: OTM 2019 Workshops, vol. 11878, C. Debruyne, H. Panetto, W. Guédria, P. Bollen, I. Ciuciu, G. Karabatis, and R. Meersman, Eds. Cham: Springer International Publishing, 2020, pp. 13-22.

[30] R. Baskerville, A. Baiyere, S. Gergor, A. Hevner, and M. Rossi, "Design Science Research Contributions: Finding a Balance between Artifact and Theory," f. Assoc. Inf. Syst., vol. 19, no. 5, pp. 358-376, May 2018, doi: 10.17705/1jais.00495.

[31] A. Hevner, "A Three Cycle View of Design Science Research," Scand. 7. Inf. Syst., vol. 19 , no. 2, pp. 87-92, 2007.

[32] K. Peffers, T. Tuunanen, M. A. Rothenberger, and S. Chatterjee, "A Design Science Research Methodology for Information Systems Research," f. Manag. Inf. Syst., vol. 24, no. 3, pp. 45-77, Dec. 2007, doi: 10.2753/MIS0742-1222240302. 